\title{
BMJ
}

\section{Early life exposure to diagnostic radiation and ultrasound scans and risk of childhood cancer: case-control study}

\author{
Preetha Rajaraman, investigator, ${ }^{1}$ jill Simpson, research fellow, ${ }^{2}$ Gila Neta, post-doctoral fellow, ${ }^{1}$ Amy
} Berrington de Gonzalez, investigator, ${ }^{1}$ Pat Ansell, senior lecturer, ${ }^{2}$ Martha S Linet, senior investigator, ${ }^{1}$ Elaine Ron, senior investigator, ${ }^{1}$ Eve Roman, professor of epidemiology ${ }^{2}$

${ }^{1}$ Division of Cancer Epidemiology and Genetics, National Cancer Institute, NIH, DHHS, 6120 Executive Blvd, Bethesda, MD 20892-7238, USA

Epidemiology and Genetics Unit, Department of Health Sciences, University of York, York, UK Correspondence to: P Rajaraman rajarama@mail.nih.gov

Cite this as: $B M J$ 2011;342:d472 doi:10.1136/bmj.d472

\section{ABSTRACT}

Objective To examine childhood cancer risks associated with exposure to diagnostic radiation and ultrasound scans in utero and in early infancy (age 0-100 days).

Design Case-control study.

Setting England and Wales.

Participants 2690 childhood cancer cases and 4858 age, sex, and region matched controls from the United Kingdom Childhood Cancer Study (UKCCS), born 197696.

Main outcome measures Risk of all childhood cancer, leukaemia, lymphoma, and central nervous system tumours, measured by odds ratios.

Results Logistic regression models conditioned on matching factors, with adjustment for maternal age and child's birth weight, showed no evidence of increased risk of childhood cancer with in utero exposure to ultrasound scans. Some indication existed of a slight increase in risk after in utero exposure to $\mathrm{x}$ rays for all cancers (odds ratio $1.14,95 \%$ confidence interval 0.90 to 1.45 ) and leukaemia (1.36, 0.91 to 2.02), but this was not statistically significant. Exposure to diagnostic $x$ rays in early infancy (0-100 days) was associated with small, non-significant excess risks for all cancers and leukaemia, as well as increased risk of lymphoma (odds ratio $5.14,1.27$ to 20.78 ) on the basis of small numbers. Conclusions Although the results for lymphoma need to be replicated, all of the findings indicate possible risks of cancer from radiation at doses lower than those associated with commonly used procedures such as computed tomography scans, suggesting the need for cautious use of diagnostic radiation imaging procedures to the abdomen/pelvis of the mother during pregnancy and in children at very young ages.

\section{INTRODUCTION}

Exposure to diagnostic radiography in utero has been associated with increased risk of childhood cancer, particularly leukaemia. ${ }^{1-3}$ Although diagnostic radiography and other radiological imaging procedures to the abdomen and pelvis of pregnant women are uncommon, potential adverse effects of exposure to radiation in early life remain a concern with the growing use of computed tomography scans and other recent types of higher dose imaging procedures. ${ }^{4}$ This is particularly the case in children, as younger age has generally been associated with higher susceptibility to the adverse effects of radiation. ${ }^{5}$ Initial findings from the Oxford Survey of Childhood Cancers, the first and largest study of in utero exposure to diagnostic radiography and risk of childhood cancer, indicated an approximately twofold risk of death from leukaemia, and from all other cancers combined, in children whose mothers had been exposed to abdominal radiography during pregnancy. ${ }^{6}$ For the calendar period 1953-81, the overall excess risk of childhood cancer associated with maternal exposure to abdominal radiography during pregnancy in the Oxford survey was approximately $40 \%$ (odds ratio $1.39,95 \%$ confidence interval 1.30 to 1.49$).{ }^{7}$ A meta-analysis of all pertinent studies of childhood cancer and leukaemia excluding the Oxford survey yielded very similar results (odds ratio $1.32,1.19$ to 1.46$).^{2}$ Relatively few studies have examined postnatal exposure to radiation in early life and risk of childhood cancer, particularly with respect to the early infancy period.

One of the key concerns about the existing data on exposure to diagnostic radiation in early life is that results from most of the studies are based on data from interviews, allowing for the distinct possibility of misclassification, recall bias, or both as regards exposure. This may be a greater problem for epidemiological studies of postnatal radiographic examinations, for which parents may not have been present.

In this analysis, we used data from the United Kingdom Childhood Cancer Study (UKCCS), a large casecontrol study of childhood cancer, to examine the risk of all childhood cancer and major subtypes of paediatric cancer after exposure to diagnostic radiation in utero and in early infancy (0-100 days). In addition, we examined the risks of childhood cancer associated with exposure to ultrasound scans in utero and in early infancy, which have generally not been associated with increased risk of childhood cancer in offspring of mothers who had ultrasound scans of the fetus during pregnancy. ${ }^{8-10}$ The availability of data abstracted from medical records, the large sample size, the relatively recent time period (children born 1976-96), and the 
ability to examine the early infancy time window make the UKCCS a particularly apt setting in which to study these hypotheses.

\section{METHODS}

Overall study design and specific aims

The United Kingdom Childhood Cancer Study (UKCCS) is a large multicentre study of childhood cancer, with data accrued from England, Scotland, and Wales. Study methods have been described in detail elsewhere. ${ }^{112}$ Briefly, all children aged 14 years or younger in England, Wales, and Scotland were potentially eligible for the study. Cases were children diagnosed between 1992 and 1996 (year of birth 1976 to 1996) as having a confirmed malignancy or having any tumour of the central nervous system. Detailed diagnostic information for cases came from the Medical Research Council's treatment trials for enrolled leukaemia cases and from one of the following sources for other malignancies: the UKCCS Group, a histopathology review database created for the study, or the individual consultant treating the child. For each cancer case, two controls were selected from the same population register as the case and matched on sex and date of birth (within one month). Most controls came from registers maintained by family health services authorities. Controls for cases from South Wales and one English authority came from general practitioners' registers.

The figure shows details of participation; 4429 case families and 11977 control families were eligible, and 3834 case families and 7619 control families were interviewed. Two eligible participating controls were targeted for each case. If one eligible control refused interview, another eligible control was chosen until two controls participated. Information collected from parents or guardians of participating children included social, occupational, and medical histories of children and parents, as well as a detailed evaluation of exposure to both non-ionising radiation (extremely low frequency electromagnetic fields) and ionising radiation. Eighty-seven per cent of eligible case families were interviewed, compared with $64 \%$ of eligible control families. Differences in the level of participation in interviews by case and control status were mainly due to differences in maternal refusal rates.

At the time of interview, parents were asked for permission for researchers to access medical records for the parents and their child. We targeted mothers of 3133 cases and 6236 controls for abstraction of obstetric notes in this study (we did not target people resident in Scotland, Avon, Dorset, Somerset, or the Isle of Wight at the time of diagnosis). For each case, we obtained records for at least one individually matched, randomly selected control. Virtually all mothers agreed to allow access to their obstetric records, but some of the records had been lost or mislaid, leading to a slight reduction in the number available for analysis. Where available, we abstracted maternal obstetric records and early infancy records by using a standardised, validated form designed to be applicable across hospitals and calendar time periods. Data abstracted for 2690 case mothers ( $86 \%$ of targeted) and 4858 control mothers $(78 \%$ of targeted) form the basis of the analyses reported here.

Information collected for in utero radiography included number of radiographs, as well as individual information on date, gestational age, and type/location

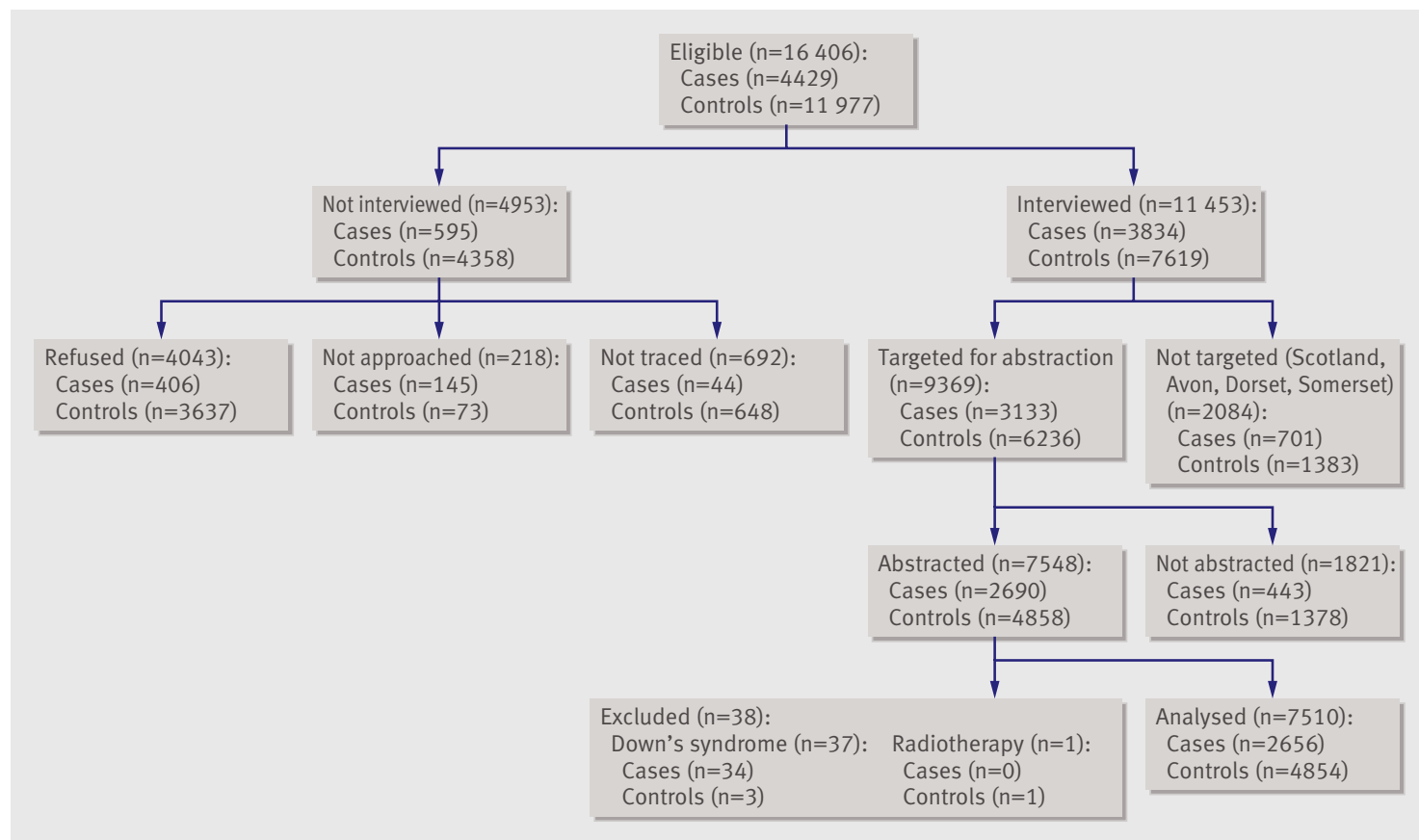

Eligibility, participation, and inclusion in analysis of early life exposure to diagnostic radiation and ultrasound scans in UK Childhood Cancer Study 
of examination. We collected similar data for radiography in early infancy. Obstetric notes for the study included only details of investigations while the baby was still in hospital. Although most children in the analysis were exposed to $x$ rays as neonates (age 0-28 days), we included in our analysis a small proportion of babies $(51 / 7548)$ who had stayed in the hospital for longer than this, usually because they were born prematurely. Of the 51 babies who stayed for longer than 28 days, most (40/51) stayed for less than 60 days and all stayed for less than 100 days. We treated cases and controls identically in terms of abstraction of extensions to the neonatal period. For in utero ultrasound scans, we collected data on the total number of scans, as well as the date, gestational age, and reason for ultrasound scan. Information collected for ultrasound scans in early infancy included the number, date, age, and type/ location of ultrasound scan (for example, abdomen, brain, heart).

\section{Statistical analyses}

To ensure uniformity of data, we restricted this analysis to data abstracted from medical records. We used the software packages SAS v9.2 and Stata/SE 11.0 to analyse data. We used conditional logistic regression to calculate odds ratios and 95\% confidence intervals to examine associations of paediatric cancer with exposure to diagnostic radiation in utero and in early infancy. The main exposure variables of interest were any exposure to diagnostic radiography in utero or in early infancy. In addition, we examined exposure to ultrasound scans in utero and in early infancy with respect to childhood cancer. All analyses were conditioned on the study matching factors of sex, age ( \pm 1 month), and study centre. We considered the following variables as potential confounders on the basis of possible association with childhood cancer or radiation: maternal age, smoking, socioeconomic status, pregnancy order, pre-eclampsia, anaemia, multiple pregnancy, child's birth weight, and admittance to the neonatal intensive care unit (table 1). After consideration of all potential confounders, we conditioned the final models on study matching factors (age, sex, study region) and adjusted them for maternal age and child's birth weight, on the basis of evidence of confounding. Models for exposure to x rays and ultrasound were mutually adjusted, as were models for exposures in utero and in early infancy. Because of the strong association between trisomy 21 (Down's syndrome) and leukaemia in the literature, and strong confounding by trisomy 21 in our dataset, we excluded 34 children with this syndrome from all analyses. We retained participants with missing data in the model as a separate category.

Additional analyses for in utero associations included restriction of exposure to in utero radiography to the abdominal region only and examination of risk by trimester of exposure and decade of exposure. For exposure in early infancy, we examined associations with exposure time lags of zero, one, and two years to check for possible biases introduced by diagnostic examinations motivated by symptoms

Table 1|Demographic characteristics of study participants* with obstetric data, UK Childhood Cancer Study 1976-96. Values are numbers (percentages) unless stated otherwise

\begin{tabular}{|c|c|c|c|c|c|}
\hline Characteristics & $\begin{array}{l}\text { All controls } \\
(\mathrm{n}=4857)\end{array}$ & $\begin{array}{l}\text { All cases } \\
(n=2690)\end{array}$ & $\begin{array}{c}\text { Leukaemia } \\
(n=1253)\end{array}$ & $\begin{array}{l}\text { Lymphoma } \\
(n=231)\end{array}$ & $\begin{array}{l}\text { Central nervous } \\
\text { system }(n=482)\end{array}$ \\
\hline \multicolumn{6}{|l|}{ Age at diagnosis (years): } \\
\hline$<1$ & $471(9.7)$ & $250(9.3)$ & $74(5.9)$ & $0(0)$ & $44(9)$ \\
\hline $1-4$ & $2233(46.0)$ & 1195 (44.4) & $665(53.1)$ & $48(21)$ & $153(32)$ \\
\hline $5-9$ & $1324(27.3)$ & $743(27.6)$ & $340(27.1)$ & $80(35)$ & $182(38)$ \\
\hline $10-14$ & 829 (17.1) & $502(18.7)$ & $174(13.9)$ & $103(45)$ & $103(21)$ \\
\hline Mean (median) age at diagnosis (years) & $5.5(4.4)$ & $5.7(4.6)$ & $5.3(4.3)$ & $9.0(9.4)$ & $6.4(6.1)$ \\
\hline Male sex & $2688(55.3)$ & $1499(55.7)$ & $692(55.2)$ & $165(71)$ & $236(49)$ \\
\hline \multicolumn{6}{|l|}{ Birth weight (g): } \\
\hline$<2500$ & $289(6.0)$ & $137(5.1)$ & $62(4.9)$ & $13(6)$ & $26(5)$ \\
\hline $2500-4000$ & $4071(83.8)$ & $2250(83.6)$ & $1046(83.5)$ & $196(85)$ & $406(84)$ \\
\hline$\geq 4000$ & $497(10.2)$ & $303(11.3)$ & $145(11.6)$ & $22(10)$ & $50(10)$ \\
\hline Multiple birth & $108(2.2)$ & $62(2.3)$ & $25(2.0)$ & $6(3)$ & $13(3)$ \\
\hline Trisomy 21 & $3(0.1)$ & $34(1.3)$ & $34(2.7)$ & $0(0)$ & $0(0)$ \\
\hline Mean (median) maternal age at birth (years) & $28.0(27.8)$ & $27.5(27.3)$ & $27.7(27.6)$ & $27.0(26.6)$ & $27.2(26.9)$ \\
\hline Maternal smoking & 1314 (27.1) & $696(25.9)$ & $323(25.8)$ & $57(25)$ & $128(27)$ \\
\hline Maternal pre-eclampsia & $481(9.9)$ & $278(10.3)$ & $127(10.1)$ & $31(13)$ & $54(11)$ \\
\hline Deprivation at birth: & $(n=4834)$ & $(n=2677)$ & $(n=1251)$ & $(n=230)$ & $(n=476)$ \\
\hline 1 (least) & $906(18.7)$ & $469(17.5)$ & $238(19.0)$ & $27(12)$ & $78(16)$ \\
\hline 2 & $1006(20.8)$ & $564(21.1)$ & $254(20.3)$ & $48(21)$ & $114(24)$ \\
\hline 3 & $1076(22.3)$ & $560(20.9)$ & $241(19.3)$ & $56(24)$ & $102(21)$ \\
\hline 4 & 994 (20.6) & $562(20.9)$ & $264(21.1)$ & $41(18)$ & $104(22)$ \\
\hline 5 (most) & $852(17.6)$ & $522(19.5)$ & $254(20.3)$ & $58(25)$ & $78(16)$ \\
\hline
\end{tabular}


Table 2 | Types of diagnostic examinations in utero and in early infancy, UK Childhood Cancer Study, 1976-96*

No (\%) of procedures; No of participants

In utero examinations

Radiation (319 procedures; 305 participants):

\begin{tabular}{|c|c|}
\hline Pelvimetry & $204(64) ; 196$ \\
\hline Chest radiography & $41(13) ; 36$ \\
\hline Abdominal radiography & $36(11) ; 29$ \\
\hline Other radiography & $19(6) ; 16$ \\
\hline Radiography for broken bone & $6(2) ; 5$ \\
\hline Skull radiography & $2(1) ; 1$ \\
\hline Computed tomography & $1(\ll 1) ; 1$ \\
\hline Uncertain & $2(1) ; 2$ \\
\hline Barium enema† & $2(1) ; 2$ \\
\hline Salpingogram $†$ & $2(1) ; 2$ \\
\hline Intravenous pyelogram $†$ & $2(1) ; 2$ \\
\hline Barium meal† & $1(\ll 1) ; 1$ \\
\hline Venograph $†$ & $1(\ll 1) ; 1$ \\
\hline More than one site & 11 participants \\
\hline \multicolumn{2}{|l|}{ Ultrasound scans (13 723 procedures; 6516 participants): } \\
\hline Confirmation of pregnancy/routine & 8683 (63.3); 3785 \\
\hline Intrauterine growth restriction scan to check fetal growth & 1434 (10.4); 46 \\
\hline Anomaly scans (routine in some hospitals) & 1010 (7.4); 244 \\
\hline Placental location & $606(4.4) ; 27$ \\
\hline Other & 1990 (14.5); 124 \\
\hline More than one reason & 2290 participants \\
\hline
\end{tabular}

Early infancy examinations

Radiation (247 procedures; 170 participants):

\begin{tabular}{lc}
\hline Chest radiography & $177(72) ; 116$ \\
\hline Skull radiography & $5(2) ; 4$ \\
\hline Radiography to look for broken bones & $5(2) ; 1$ \\
\hline Other & $55(22) ; 29$ \\
\hline Barium meal† & $2(1) ; 1$ \\
\hline Barium enema† & $2(1) ; 1$ \\
\hline Intravenous pyelogram† & $1($ («); 1 \\
\hline More than one site & 17 participants \\
\hline Ultrasound scans (138 procedures; 107 participants): & \\
\hline Brain & $42(30) ; 27$ \\
\hline Hips/pelvis & $33(24) ; 28$ \\
\hline Kidney & $26(19) ; 19$ \\
\hline Abdominal & $12(9) ; 9$ \\
\hline Echocardiogram & $7(5) ; 5$ \\
\hline Chest & $2(1) ; 1$ \\
\hline Neck & $1(1) ; 1$ \\
\hline Other & $15(11) ; 9$ \\
\hline More than one site & 8 participants \\
\hline
\end{tabular}

*Excluding participants with trisomy 21 and one participant with radiotherapy. For participant level breakdowns, several children had examinations to more than one site or for more than one reason.

†Radionuclide examinations. ever/never radiography variable and "unexposed" for the ever/never radiography with a one year lag variable. Participants who received a diagnosis at an age younger than the lag period had no childhood radiographs or scans assigned. Additionally, we analysed all models stratified by age of diagnosis of cancer ( $<5$ years $v 5$-14 years). Finally, we ran models that excluded neonates who stayed in the hospital for longer than 28 days.

\section{RESULTS}

Table 1 summarises the demographic characteristics of cases and controls. Most cases of cancer were diagnosed between the ages of 1 and 5 years, with a slight predominance of boys $(\mathrm{n}=1195 ; 44.4 \%)$. Cases and controls were similar in terms of birth weight, although leukaemia cases were slightly heavier. The number of multiple births was similar for cases and controls, whereas cases were more likely to have trisomy 21 (excluded from analysis) and case mothers were more likely to have had maternal pre-eclampsia than were mothers of controls. Mothers of controls from more deprived areas were less likely to participate and were slightly, non-significantly, older than case mothers.

In this study population, 305 children received 319 radiographic and related examinations in utero and 170 children received 247 diagnostic radiographic examinations in early infancy. The most common in utero examination was pelvimetry $(n=204 ; 64 \%$ of all radiographic examinations), and the most common examination in early infancy was chest radiography ( $n=177 ; 72 \%$ of examinations) (table 2 ). In utero diagnostic radiographic examinations were much less frequent than ultrasound scans in controls $(185 / 4854$ or $3.8 \%$ v $4234 / 4854$ or $87 \%$ ). Of the participants who received in utero radiography, only $14(5 \%)$ had two radiographs, whereas $41(24 \%)$ of the infants who received postnatal radiography had more than one examination: $24(14 \%)$ had two examinations, and 6 $(4 \%)$ had more than three radiographic examinations. A total of 13723 ultrasound scans in utero and 138 in early infancy were done; in utero ultrasound scans were mainly done as routine examinations to confirm pregnancy or to check fetal growth. Ultrasound examinations of the brain were the most common type of ultrasound examination in the early infancy period $(\mathrm{n}=42 ; 30 \%)$.

We found some indication of a slightly elevated risk for all cancers after in utero exposure to $\mathrm{x}$ rays (odds ratio $1.14,95 \%$ confidence interval 0.90 to 1.45 ), but this was not statistically significant. Although numbers were small, this association was most apparent for leukaemia (odds ratio $1.36,0.91$ to 2.02 ), particularly acute myeloid leukaemia $(2.44,0.95$ to 6.33$)$ (table 3$)$. Results were similar after we added pregnancy order to the models; the association seemed slightly stronger for acute myeloid leukaemia (odds ratio 2.73, 1.04 to 7.13). Restriction to pelvimetry and other in utero radiography of the abdominal region produced similar, although somewhat attenuated, results (odds ratio 
for acute myeloid leukaemia $1.76,0.63$ to 4.90 , on the basis of eight exposed cases and eight exposed controls) (table 4). When we examined risk by decade of in utero exposure to diagnostic radiation, risk estimates for radiographic exposure were higher in the 1970s than for diagnostic radiography in following decades, particularly for leukaemia (five exposed cases; odds ratio $3.58,0.54$ to 23.68 ), although numbers were small. Risk for childhood cancer associated with in utero radiographic exposure was similar regardless of trimester of first exposure (table 4). Results of in utero models stratified by age at diagnosis indicated that associations were most apparent when age of diagnosis was greater than 5 years (odds ratio for cancer 1.22, 0.90 to 1.65 , for age $>5$ years $v 1.01,0.68$ to 1.50 , for age $\leq 5$ years; odds ratio for leukaemia $1.51,0.91$ to 2.52 , for age $>5$ years $v 1.15,0.61$ to 2.20 , for age $\leq 5$ years). We found no increased risk of childhood cancer after exposure to in utero ultrasound scans (odds ratio 0.93, 0.79 to 1.09 ) (table 3 ).

Exposure to diagnostic radiography in early infancy was associated with a slight indication of elevated risk for all childhood cancers (odds ratio 1.16, 0.83 to 1.62 ) and leukaemia (1.39, 0.87 to 2.23$)$, particularly acute myeloid leukaemia $(1.63,0.42$ to 6.35$)$ with no exposure lag, but these associations were not statistically significant (table 5). Although based on only seven exposed cases, the strongest signal was for lymphoma (odds ratio $5.14,1.27$ to 20.78 ). Most (4/7) of these babies were premature, had multiple chest radiography examinations, and were diagnosed as having lymphoma after the age of 10 years. Results for risk of cancer associated with exposure to diagnostic radiography for models with zero, one, and two year lags for exposure were similar.
Although we found a suggestion of increased risk of childhood cancer after exposure to ultrasound scans in early infancy, this association was attenuated and no longer statistically significant when we introduced a two year lag for exposure to scans (table 5). We found no relation between exposure to ultrasound scans in early infancy and risk of leukaemia (odds ratio $0.95,0.49$ to 1.86 ) or lymphoma. Restriction of models to neonates who stayed in the hospital for 28 days or less did not materially alter results for in utero radiographic or ultrasound examinations. Numbers were too small for us to be able to assess the relation between radiographs in neonates (0-28 days) and lymphoma.

\section{DISCUSSION}

Our study indicated a slight, non-statistically significant increase in risk after in utero exposure to $\mathrm{x}$ rays for all cancers (odds ratio 1.14, 95\% confidence interval 0.90 to 1.45$)$ and leukaemia $(1.36,0.91$ to 2.02$)$, particularly acute myeloid leukaemia. Exposure to diagnostic radiography in early infancy was associated with small, non-significant excess risks for all cancers and leukaemia, as well as increased risk of lymphoma (odds ratio 5.14, 1.27 to 20.78) on the basis of small numbers. We found no evidence of increased risk of childhood cancer with in utero exposure to ultrasound scans.

\section{Relevance of study}

The question of the risk of cancer associated with diagnostic radiography or other imaging procedures involving ionising radiation in utero or in childhood is particularly relevant at the moment given the growing use of diagnostic examinations, especially computed

Table 3 | Odds ratios ( $95 \%$ confidence intervals) for childhood cancer associated with any in utero exposure to radiation and ultrasound scans, UK Childhood Cancer Study, 1976-96*

\begin{tabular}{|c|c|c|c|c|c|c|}
\hline \multirow[b]{2}{*}{ Cancer } & \multicolumn{3}{|c|}{ Radiation exposure } & \multicolumn{3}{|c|}{ Ultrasound exposure } \\
\hline & $\begin{array}{c}\text { No of cases } \\
\text { exposed }\end{array}$ & $\begin{array}{c}\text { No of controls } \\
\text { exposed }\end{array}$ & Odds ratio $†$ & $\begin{array}{c}\text { No of cases } \\
\text { exposed }\end{array}$ & $\begin{array}{c}\text { No of controls } \\
\text { exposed }\end{array}$ & Odds ratio $†$ \\
\hline All cancers & 120 & 185 & $1.14(0.90$ to 1.45$)$ & 2282 & 4234 & $0.93(0.79$ to 1.09$)$ \\
\hline Leukaemia: & 48 & 62 & 1.36 (0.91 to 2.02$)$ & 1074 & 2034 & $0.87(0.68$ to 1.11$)$ \\
\hline Acute lymphoid & 36 & 53 & $1.20(0.76$ to 1.88$)$ & 913 & 1726 & $0.83(0.63$ to 1.09$)$ \\
\hline Acute myeloid & 11 & 8 & $2.44(0.95$ to 6.33$)$ & 144 & 273 & $1.28(0.64$ to 2.56$)$ \\
\hline Chronic myeloid & 1 & 1 & - & 15 & 33 & $0.47(0.06$ to 3.56$)$ \\
\hline Lymphoma: & 16 & 30 & $1.06(0.55$ to 2.06$)$ & 182 & 310 & $1.25(0.80$ to 1.95$)$ \\
\hline Non-Hodgkin's & 13 & 18 & $1.48(0.66$ to 3.32$)$ & 131 & 224 & $1.30(0.75$ to 2.25$)$ \\
\hline Hodgkin's & 3 & 12 & - & 46 & 80 & 1.03 (0.46 to 2.34$)$ \\
\hline Brain/central nervous system & 25 & 41 & $1.06(0.64$ to 1.77$)$ & 408 & 731 & $1.08(0.77$ to 1.52$)$ \\
\hline Sarcoma & 10 & 15 & 1.13 (0.49 to 2.61$)$ & 142 & 271 & 0.69 (0.39 to 1.22$)$ \\
\hline Peripheral neural tumours & 7 & 13 & $1.00(0.37$ to 2.67$)$ & 155 & 288 & 0.88 (0.46 to 1.69$)$ \\
\hline Renal & 5 & 6 & 1.64 (0.48 to 5.59$)$ & 130 & 252 & $0.56(0.28$ to 1.13$)$ \\
\hline Retinoblastoma & 2 & 5 & - & 64 & 118 & $0.84(0.19$ to 3.71$)$ \\
\hline Gonadal & 1 & 6 & - & 51 & 92 & 1.04 (0.34 to 3.18) \\
\hline Hepatic & 0 & 3 & - & 22 & 41 & $0.88(0.11$ to 6.80$)$ \\
\hline
\end{tabular}

*Participants with trisomy 21 and one participant with radiotherapy excluded from analysis. Results not shown for categories with fewer than five exposed cases.

†Adjusted for sex of child, age at diagnosis, UKCCS study region, birth weight, maternal age, early infancy radiation (1 year lag), and early infancy ultrasound scans (1 year lag); radiation and ultrasound exposure each adjusted for other 
Table $4 \mid$ Odds ratios ( $95 \%$ confidence intervals) for childhood cancer associated with in utero exposure to diagnostic radiation, by decade of birth, by trimester of exposure, and restricted to abdominal exposure, UK Childhood Cancer Study, 1976-96*

\begin{tabular}{|c|c|c|c|c|c|c|}
\hline \multirow[b]{2}{*}{ Exposure } & \multicolumn{3}{|c|}{ All cancers } & \multicolumn{3}{|c|}{ Leukaemia } \\
\hline & $\begin{array}{l}\text { No of cases } \\
\text { exposed }\end{array}$ & $\begin{array}{c}\text { No of controls } \\
\text { exposed }\end{array}$ & Odds ratio† & $\begin{array}{c}\text { No of cases } \\
\text { exposed }\end{array}$ & $\begin{array}{c}\text { No of controls } \\
\text { exposed }\end{array}$ & Odds ratio† \\
\hline \multicolumn{7}{|l|}{ Exposure to $\mathrm{x}$ ray: } \\
\hline Born in $1970 \mathrm{~s}$ & 12 & 14 & $1.37(0.60$ to 3.13$)$ & 5 & 3 & 3.58 (0.54 to 23.68$)$ \\
\hline Born in $1980 \mathrm{~s}$ & 70 & 116 & $1.06(0.78$ to 1.45$)$ & 26 & 36 & 1.24 (0.73 to 2.11$)$ \\
\hline Born in 1990s & 38 & 55 & $1.23(0.80$ to 1.90$)$ & 17 & 23 & 1.31 (0.68 to 2.53$)$ \\
\hline \multicolumn{7}{|l|}{ Exposure to $x$ ray: } \\
\hline Trimester 1 & 7 & 9 & 1.27 (0.47 to 3.48$)$ & 2 & 2 & - \\
\hline Trimester 2 & 12 & 17 & 1.08 (0.51 to 2.28$)$ & 4 & 5 & - \\
\hline Trimester 3 & 93 & 152 & $1.09(0.83$ to 1.43$)$ & 37 & 52 & 1.27 (0.81 to 1.98$)$ \\
\hline $\begin{array}{l}\text { Restricted to abdominal } \\
\text { radiography }\end{array}$ & 90 & 143 & $1.12(0.85$ to 1.48$)$ & 37 & 54 & 1.21 (0.78 to 1.88$)$ \\
\hline
\end{tabular}

tomography scans, in children. ${ }^{13}$ Although several studies have indicated that in utero exposure to radiation from diagnostic radiography is associated with increased risk of childhood cancer, the association between postnatal diagnostic imaging scans and risk of childhood cancer remains unclear. ${ }^{1-3}$ Most previous studies, including the largest case-control study of childhood cancer to date (the Oxford Survey of Childhood Cancers), have used interview based data to infer exposure to radiological procedures.

\section{Comparison with previous studies}

Using data abstracted from medical records, we found that in utero exposure to diagnostic radiation was associated with a statistically non-significant increase in overall childhood cancer (odds ratio 1.14, 95\% confidence interval 0.90 to 1.45 ) in children born in 1976-96 in the United Kingdom. These estimates are consistent with results for maternal abdominal exposures and childhood cancer from the Oxford Survey of Childhood Cancers (odds ratio 1.39, 1.30 to 1.49 ) in children born between 1943 and $1967,{ }^{7}$ as well results from a medical record based study in the eastern United States in children born in 1947 to 1960 (unadjusted relative risk $1.47,1.22$ to 1.77$).{ }^{14}$ The lower magnitude of risk observed in our study would be expected on the basis of the decrease in risk by decade seen in the Oxford survey, which the authors ascribed to lower doses per image and fewer images per patient. ${ }^{7}$ We also saw a decline in risk by decade of exposure in our study. The prevalence of radiography in controls in our study in the $1980 \mathrm{~s}$ and $1990 \mathrm{~s}$ was $3.8 \%$, compared with $10-15 \%$ in the Oxford survey in the 1950 s to 1970s. ${ }^{15}$ A large interview based US case-control study of diagnostic radiography and leukaemia also noted a declining proportion of mothers having pelvimetry during pregnancy with later calendar periods $(10.2 \%, 2.4 \%$, and $1.3 \%$ of cases and $6.0 \%, 2.3 \%$, and $1.8 \%$ of controls born in 1980 or earlier, 1981-6, or after 1986). ${ }^{10}$ Consistent with the notion of declining number of images per patient over time, only $5 \%$ of participants were exposed to more than one radiographic film in our study, as opposed to approximately $57 \%$ of those in the earlier calendar period of the Oxford survey. ${ }^{16}$

Our estimate of the excess risk associated with in utero diagnostic radiation for leukaemia specifically (odds ratio $1.36,0.91$ to 2.02 ) is similar to estimates reported by the Oxford survey $(1.49,1.33$ to 1.67$),{ }^{16}$ a subsequent meta-analysis of childhood studies and leukaemia excluding data from the Oxford survey $(1.32,1.19$ to 1.46$),{ }^{2}$ and a study of medical record data from the northeastern United States (unadjusted odds ratio $1.48,1.18$ to 1.85$).{ }^{214}$ In an earlier analysis of perinatal and reproductive factors and risk of haematological malignancies in the UK Childhood Cancer Study using all controls for comparison, the risk of leukaemia was found to be 1.1 ( 0.8 to 1.5$)$ with any in utero exposure to radiography. ${ }^{12}$

One of the main reasons for controversy about the association between in utero exposure to diagnostic radiography and risk of childhood cancer has been the lack of specificity of an association by cancer type in the Oxford survey. ${ }^{7}$ Although our numbers are small for estimates of specific cancer subtypes, our results indicate some degree of specificity of the association of in utero exposure to $\mathrm{x}$ rays with risk of leukaemia, particularly acute myeloid leukaemia. This is consistent with previous literature reporting that acute myeloid leukaemia is the subtype of leukaemia most strongly associated with radiation in populations including atomic bomb survivors and radiation workers. ${ }^{17} 18$

Although our results for exposure to diagnostic radiation in early infancy and risk of overall childhood cancer were not statistically significant, we found some suggestion of increased risk of leukaemia (odds ratio 1.35, 0.81 to 2.27 , particularly of acute myeloid leukaemia, with exposure to $\mathrm{x}$ rays in early infancy. Results of the Oxford Survey of Childhood Cancer did not indicate 
Table 5 |Odds ratios (95\% confidence intervals) for childhood cancer associated with any exposure to diagnostic radiation or ultrasound scans in early infancy (0-100 days), UK Childhood Cancer Study, 1976-96*

\begin{tabular}{|c|c|c|c|c|c|c|c|c|}
\hline \multirow[b]{3}{*}{ Cancer } & \multicolumn{4}{|c|}{ Early infancy radiation exposure } & \multicolumn{4}{|c|}{ Early infancy ultrasound scan exposure } \\
\hline & \multicolumn{2}{|c|}{0 year lag } & \multicolumn{2}{|c|}{2 year lag } & \multicolumn{2}{|c|}{0 year lag } & \multicolumn{2}{|c|}{2 year lag } \\
\hline & $\begin{array}{l}\text { No of cases/ } \\
\text { controls } \\
\text { exposed }\end{array}$ & Odds ratio $†$ & $\begin{array}{c}\text { No of cases/ } \\
\text { controls } \\
\text { exposed }\end{array}$ & Odds ratio $†$ & $\begin{array}{c}\text { No of cases/ } \\
\text { controls } \\
\text { exposed }\end{array}$ & Odds ratio $†$ & $\begin{array}{c}\text { No of cases/ } \\
\text { controls } \\
\text { exposed }\end{array}$ & Odds ratio $†$ \\
\hline All cancers & $68 / 102$ & $\begin{array}{c}1.16 \\
\text { (0.83 to } 1.62)\end{array}$ & $50 / 75$ & $\begin{array}{c}1.19 \\
(0.82 \text { to } 1.74)\end{array}$ & $49 / 58$ & $\begin{array}{c}1.92 \\
(1.25 \text { to } 2.95)\end{array}$ & $25 / 33$ & $\begin{array}{c}1.55 \\
\text { (0.89 to } 2.70)\end{array}$ \\
\hline Leukaemia: & $34 / 49$ & $\begin{array}{c}1.39 \\
\text { (0.87 to } 2.23)\end{array}$ & $27 / 40$ & $\begin{array}{c}1.35 \\
(0.81 \text { to } 2.27)\end{array}$ & $16 / 35$ & $\begin{array}{c}0.95 \\
(0.49 \text { to } 1.86)\end{array}$ & $9 / 25$ & $\begin{array}{c}0.68 \\
(0.30 \text { to } 1.53)\end{array}$ \\
\hline Acute lymphoid & $29 / 43$ & $\begin{array}{c}1.41 \\
(0.85 \text { to } 2.35)\end{array}$ & $26 / 34$ & $\begin{array}{c}1.55 \\
(0.90 \text { to } 2.67)\end{array}$ & $13 / 33$ & $\begin{array}{c}0.74 \\
(0.36 \text { to } 1.52)\end{array}$ & $9 / 25$ & $\begin{array}{c}0.65 \\
(0.29 \text { to } 1.45)\end{array}$ \\
\hline Acute myeloid & $5 / 5$ & $\begin{array}{c}1.63 \\
(0.42 \text { to } 6.35)\end{array}$ & $1 / 5$ & - & $3 / 2$ & - & $0 / 0$ & - \\
\hline Chronic myeloid & $0 / 0$ & - & $0 / 0$ & - & $0 / 0$ & - & $0 / 0$ & - \\
\hline Lymphoma & $7 / 3$ & $\begin{array}{c}5.14 \\
\text { (1.27 to } 20.78)\end{array}$ & $7 / 3$ & $\begin{array}{c}5.14 \\
(1.27 \text { to } 20.8)\end{array}$ & $1 / 0$ & - & $1 / 0$ & - \\
\hline Non-Hodgkin's & $6 / 2$ & $\begin{array}{c}6.85 \\
\text { (1.31 to 35.69) }\end{array}$ & $6 / 2$ & $\begin{array}{c}6.85 \\
(1.31 \text { to } 35.7)\end{array}$ & $1 / 0$ & - & $1 / 0$ & - \\
\hline Hodgkin's & $1 / 0$ & - & $1 / 0$ & - & $0 / 0$ & - & $0 / 0$ & - \\
\hline Brain/central nervous system & $9 / 16$ & $\begin{array}{c}0.90 \\
\text { (0.36 to } 2.31)\end{array}$ & $6 / 10$ & $\begin{array}{c}0.94 \\
(0.31 \text { to } 2.92)\end{array}$ & $6 / 7$ & $\begin{array}{c}1.90 \\
(0.59 \text { to } 6.17)\end{array}$ & $4 / 2$ & - \\
\hline Peripheral neural tumours & $5 / 12$ & $\begin{array}{c}0.26 \\
(0.05 \text { to } 1.33)\end{array}$ & $2 / 8$ & - & $8 / 5$ & $\begin{array}{c}8.79 \\
\text { (1.64 to } 47.15)\end{array}$ & $1 / 2$ & - \\
\hline Sarcoma & $4 / 8$ & - & $3 / 5$ & - & $4 / 3$ & - & $3 / 3$ & - \\
\hline Renal & $4 / 6$ & - & $3 / 5$ & - & $6 / 4$ & $\begin{array}{c}3.77 \\
(0.87 \text { to } 16.36)\end{array}$ & $5 / 0$ & - \\
\hline Hepatic & $2 / 1$ & - & $1 / 0$ & - & $4 / 0$ & - & $2 / 0$ & - \\
\hline Gonadal & $1 / 2$ & - & $0 / 1$ & - & $2 / 2$ & - & $0 / 1$ & - \\
\hline Retinoblastoma & $1 / 2$ & - & $0 / 0$ & - & $2 / 2$ & - & $0 / 0$ & - \\
\hline
\end{tabular}

*Participants with trisomy 21 and one participant with radiotherapy excluded from analysis. Results not shown for categories with fewer than five exposed cases.

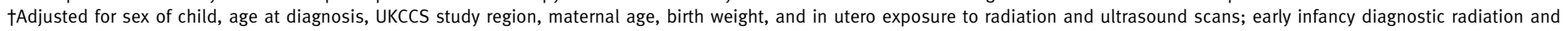
ultrasound scans each adjusted for other.

a statistically significant increased risk of childhood cancer with postnatal exposure (odds ratio 1.09, 0.83 to 1.43). ${ }^{219}$ Most studies of all childhood cancer or leukaemia done after the Oxford survey have also reported small, non-statistically significant increases in risk. ${ }^{1}$ The Oxford survey and most other studies of postnatal irradiation and risk of childhood cancer have been based on interview data, which could result in considerable misclassification. This is likely to be more of a problem for radiation in early infancy than for in utero radiation, for which mothers would necessarily have been present at the time of radiation. For radiation in early infancy, mothers are unlikely to have been present for examinations done in the neonatal or intensive care unit. One early study using information from medical records when doses of radiation were likely to be higher found an increased risk of leukaemia with postnatal exposure to more than one site (odds ratio 2.3; $\mathrm{P}=0.001) .^{20}$

We found an unexpected statistically significant increase in risk of lymphoma (odds ratio 5.14, 1.27 to 20.78 ) with exposure to diagnostic radiation in early infancy. Although most previous studies of postnatal diagnostic radiation in children have not specifically reported on risk of lymphoma, a previous interview based study in China reported a non-statistically significant increase in risk for this cancer (odds ratio 1.3, 0.6 to
2.7). ${ }^{21}$ The same study reported that for prenatal exposure to diagnostic radiation, the relation seemed to be stronger for lymphoma than for leukaemia. Evidence that low level radiation may be associated with lymphoma includes a small increase in risk of lymphoma reported in a study of offspring of US radiology technologists exposed to an estimated in utero dose of $>0 \mathrm{mGy}$ to $0.17 \mathrm{mGy}$ of radiation during pregnancy (hazard ratio $2.3,1.1$ to 4.9$),{ }^{22}$ increased mortality due to lymphoma observed in male radiologists in the UK (standardised mortality ratio $3.08 ; \mathrm{P}<0.001),{ }^{23}$ and an increase in lymphoma in male (but not female) atomic bomb survivors (excess absolute risk 0.6 cases per $10^{4}$ person year Sv). ${ }^{24}$ However, other studies, including studies of nuclear workers and patients treated with radiotherapy for benign disease, ${ }^{1825}$ have not found excess risk of lymphoma with exposure to radiation. A recent scientific review concluded that evidence for an association between external exposure to radiation and non-Hodgkin's lymphoma was mixed and that limited data indicated no evidence of an association with Hodgkin's disease. ${ }^{26}$ Given that several of the children who were diagnosed as having lymphoma in our study were born prematurely $(n=4)$ or had low birth weight $(n=3)$, these children may have been predisposed to lymphoma for some reason other than exposure to diagnostic radiography. 


\section{WHAT IS ALREADY KNOWN ON THIS TOPIC}

Studies in earlier calendar time periods have reported that in utero exposure to radiation from diagnostic radiography is associated with increased risk of childhood cancer

The association between postnatal radiographs and risk of childhood cancer has been unclear, and ultrasound scans have not been associated with risk of childhood cancer

Most published studies on prenatal and postnatal radiography used data from interviews with parents

\section{WHAT THIS STUDY ADDS}

Data from medical records showed no excess risk of childhood cancer with in utero exposure to ultrasound scans and statistically non-significant increases in risk of all childhood cancers and leukaemia with in utero exposure to $x$ rays

Exposure to diagnostic radiography in early infancy (0-100 days) was associated with a small increase in risk of all childhood cancer and leukaemia and a statistically significant increase in lymphoma

Caution is needed in the use of diagnostic radiation imaging procedures to the abdomen/ pelvis of the mother during pregnancy and in children at very young ages

\section{Strengths and limitations of study}

Strengths of our study include the large number of cases, the use of medical records to assess exposure to diagnostic radiography, and the availability of detailed information on other exposures to assess possible confounding. Unlike most previous studies, we were able to determine exposure to radiography in early infancy from medical records, which is likely to have resulted in increased accuracy of assessment of exposure. Although mothers of controls from more deprived areas were less likely to participate and mothers of case children seemed to be slightly younger than mothers of controls, these factors are unlikely to have affected whether radiographs/scans were used in pregnancy or early life, given that treatment would have been provided at no charge by the National Health Service. Despite the large number of cases of childhood cancer, our study is limited by low power to detect a small increase in risk because of the low prevalence of exposure to diagnostic radiation, as well as probable decreases in doses of radiation over time. Given the small numbers, separating the effects of time since exposure and decade of exposure in our analysis is difficult, so that lower risks for more recent time periods could be due to either lower doses or lower risks with time since exposure. Finally, we cannot rule out the possibility that the increased risk of lymphoma in children exposed to radiography in early infancy may be due to some factor related to disease.

\section{Conclusions and policy implications}

Despite the above limitations, our results are entirely consistent with previous studies reporting that in utero exposure to $\mathrm{x}$ rays is associated with increased risk of childhood cancer. Although mainly not statistically significant, the magnitude of most of the odds ratios for specific childhood cancer sites after in utero exposure exceeded 1.0, indicating a consistent picture of a modestly elevated risk. Our finding that diagnostic radiography in early infancy may be associated with a modestly increased risk of lymphoma needs confirmation. The fact that, similar to previous studies ${ }^{8-10}$ we did not see an association between exposure to ultrasound scans and risk of childhood cancer argues against a systematic bias in our results.

Our results are particularly relevant in the face of growing use of diagnostic radiation characterised by higher doses (such as computed tomography scans) in children. Reported doses for fetal exposure from maternal irradiation vary widely depending on the calendar period, type of examination, level of exposure to radiation of the mother, and anatomical site of irradiation. Estimates range from $<0.01 \mathrm{mGy}$ to 89 $\mathrm{mGy}$; the fetal dose from radiography to the abdomen or pelvis was thought to be in the order of $10 \mathrm{mGy}$ in the Oxford survey and has been estimated to be 1.3 mGy to 3.4 mGy in more recent years. ${ }^{115}$ Radiation doses received by neonates also vary by age at diagnostic procedure and other parameters, but the entrance surface dose for chest radiography has been estimated to be approximately $0.06 \mathrm{mGy}$ to $0.08 \mathrm{mGy}$ for 0-1 year olds. These doses are less than those thought to occur from computed tomography scans at the same age $(2.3 \mathrm{mSv}$ to $11.4 \mathrm{mSv}$, depending on age and body location). ${ }^{1}$ Our results, which indicate possible risks of cancer from radiation at doses lower than those associated with computed tomography scans, suggest a need for cautious use of diagnostic radiation imaging procedures to the abdomen/pelvis of the mother during pregnancy and in children at very young ages.

We thank Emily Steplowski of Information Management Systems for help with statistical programming. We especially thank the families of children included in the study, without whom this investigation would not have been possible.

Contributors: All authors contributed to the design and conduct of the study, critically reviewed manuscript drafts, and approved the final version. PR and ERoman are the guarantors.

Funding: This research was supported in part by intramural funds from the National Cancer Institute, National Institutes of Health, Department of Health and Human Services, USA. The content of this publication does no necessarily reflect the views or policies of the Department of Health and Human Services, nor does mention of trade names, commercial products, or organisations imply endorsement by the US government. The United Kingdom Childhood Cancer Study (UKCCS) is sponsored and administered by Leukaemia and Lymphoma Research. The UKCCS was conducted by 12 teams of investigators ( 10 clinical and epidemiological and two biological) based in university departments, research institutes, and the National Health Service in Scotland. Its work is coordinated by a management committee. The researchers are independent from the funders.

Competing interests: All authors have completed the Unified Competing Interest form at www.icmje.org/coi_disclosure.pdf (available on request from the corresponding author) and declare no relationships with companies that might have an interest in the submitted work in the previous three years and no non-financial interests that may be relevant to the submitted work.

Ethical approval: Initial approval for the study was obtained individually from all local ethics committees in Great Britain. Updated approval was obtained in 2005 from the Northern and Yorkshire Multi-Centre Research Ethics Committees (REC reference number 05/MRE03/22). Data sharing: No additional data available.

1 Linet MS, Kim KP, Rajaraman P. Children's exposure to diagnostic medical radiation and cancer risk: epidemiologic and dosimetric considerations. Pediatr Radiol 2009;39(suppl 1):S4-26.

2 Wakeford R. Childhood leukaemia following medical diagnostic exposure to ionizing radiation in utero or after birth. Radiat Prot Dosimetry 2008;132:166-74. 
3 Schulze-Rath R, Hammer GP, Blettner M. Are pre- or postnatal diagnostic X-rays a risk factor for childhood cancer? A systematic review. Radiat Environ Biophys 2008;47:301-12.

4 Mettler FA Jr, Thomadsen BR, Bhargavan M, Gilley DB, Gray JE, Lipoti JA, et al. Medical radiation exposure in the US in 2006: preliminary results. Health Phys 2008;95:502-7.

5 Committee to Assess Health Risks from Exposure to Low Levels of lonizing Radiation. Health risks from exposure to low levels of ionizing radiation: BEIR VII phase 2. National Research Council, National Academies of Science, 2006.

6 Stewart AWJ, Giles D, Hewitt D. Malignant disease in childhood and diagnostic irradiation in utero. Lancet 1956;2:447.

7 Doll R, Wakeford R. Risk of childhood cancer from fetal irradiation. $B r$ J Radiol 1997;70:130-9.

8 Sorahan T, Lancashire R, Stewart A, Peck I. Pregnancy ultrasound and childhood cancer: a second report from the Oxford Survey of Childhood Cancers. Br J Obstet Gynaecol 1995;102:831-2.

9 Cartwright RA, McKinney PA, Hopton PA, Birch JM, Hartley AL Mann JR, et al. Ultrasound examinations in pregnancy and childhood cancer. Lancet 1984;2:999-1000.

10 Shu XO, Potter JD, Linet MS, Severson RK, Han D, Kersey JH, et al. Diagnostic X-rays and ultrasound exposure and risk of childhood acute lymphoblastic leukemia by immunophenotype. Cancer Epidemiol Biomarkers Prev 2002;11:177-85.

11 UK Childhood Cancer Study Investigators. The United Kingdom Childhood Cancer Study: objectives, materials and methods. $\mathrm{Br}$ J Cancer 2000;82:1073-102.

12 Roman E, Simpson J, Ansell P, Lightfoot T, Mitchell C, Eden TO. Perinatal and reproductive factors: a report on haematological malignancies from the UKCCS. Eur J Cancer 2005;41:749-59.

13 Brenner DJ, Hall EJ. Computed tomography-an increasing source of radiation exposure. N Engl J Med 2007;357:2277-84.

14 Monson R, MacMahon B. Prenatal X-ray exposure and cancer in children. In: Boice JJF, Fraumeni J, eds. Radiation carcinogenesis: epidemioloogy and biological significance. Raven Press, 1984.

15 Mole RH. Childhood cancer after prenatal exposure to diagnostic Xray examinations in Britain. Br J Cancer 1990;62:152-68.
16 Bithell JF, Stewart AM. Pre-natal irradiation and childhood malignancy: a review of British data from the Oxford Survey. Br Cancer 1975;31:271-87.

17 Richardson D, Sugiyama H, Nishi N, Sakata R, Shimizu Y, Grant EJ, et al. Ionizing radiation and leukemia mortality among Japanese atomic bomb survivors, 1950-2000. Radiat Res 2009;172:368-82.

18 Cardis E, Vrijheid M, Blettner M, Gilbert E, Hakama M, Hill C, et al. The 15-country collaborative study of cancer risk among radiation workers in the nuclear industry: estimates of radiation-related cancer risks. Radiat Res 2007;167:396-416.

19 Stewart A, Webb J, Hewitt D. A survey of childhood malignancies. BMJ 1958;1:1495-508.

20 Graham S, Levin ML, Lilienfeld AM, Schuman LM, Gibson R, Dowd JE, et al. Preconception, intrauterine, and postnatal irradiation as related to leukemia. Natl Cancer Inst Monogr 1966;19:347-71.

21 Shu XO, Jin F, Linet MS, Zheng W, Clemens J, Mills J, et al. Diagnostic $\mathrm{X}$-ray and ultrasound exposure and risk of childhood cancer. $\mathrm{Br}$ J Cancer 1994;70:531-6.

22 Johnson KJ, Alexander BH, Doody MM, Sigurdson AJ, Linet MS, Spector LG, et al. Childhood cancer in the offspring born in 1921 1984 to US radiologic technologists. Br J Cancer 2008;99:545-50.

23 Berrington A, Darby SC, Weiss HA, Doll R. 100 years of observation on British radiologists: mortality from cancer and other causes 1897 1997. Br J Radiol 2001;74:507-19.

24 Preston DL, Kusumi S, Tomonaga M, Izumi S, Ron E, Kuramoto A, et al. Cancer incidence in atomic bomb survivors. Part III. Leukemia, lymphoma and multiple myeloma, 1950-1987. Radiat Res 1994;137:S68-97.

25 Inskip PD, Kleinerman RA, Stovall M, Cookfair DL, Hadjimichael O Moloney WC, et al. Leukemia, lymphoma, and multiple myeloma after pelvic radiotherapy for benign disease. Radiat Res 1993;135:108-24

26 United Nations Scientific Committee on the Effects of Atomic Radiation. Effects of ionizing radiation. United Nations, 2006.

Accepted: 1 November 2010 